\title{
A Cross-cultural study of college-age females' body satisfaction and clothing choices
}

\begin{abstract}
This survey-based cross-cultural study was conducted to explore college-age females' concerns and appreciation of their physical bodies in two countries dominated by different beauty standards. It also investigated the relationship between body satisfaction of collegeage women and their clothing choices in two different cultural settings. Three hundred and thirteen valid responses were collected in the United States and one hundred and ninetyfour valid ones were collected in China. Findings suggest that United States participants are in a complicated love-hate relationship with their middle to lower body parts, while Chinese participants are clearer about their favorite and least favorite body parts. The clothing choices of both groups were greatly affected by their perception and satisfaction level of their own physical body. However, neither group believed that body perceptions and clothing choices were influenced by media.
\end{abstract}

Keywords: body image, body satisfaction, cross-cultural study, beauty standards
Volume 4 Issue 2 - 2018

\author{
Yingying Wu,' Ping Xiao, ${ }^{2}$ Susan P Ashdown ${ }^{3}$ \\ 'Department of Apparel, Textiles, and Interior Design, Kansas \\ State University, USA \\ ${ }^{2}$ Fashion \& Art Design Institute, Donghua University, China \\ ${ }^{3}$ Department of Fiber Science and Apparel Design, Cornel \\ University, USA
}

Correspondence: Yingying Wu, Department of Apparel, Textiles and Interior Design, Kansas State University, 320 Justin Hall, I 324 Lovers Lane, Manhattan, Kansas, USA, Email yingyingwu9@ksu.edu

Received: October 27, 2017 | Published: April 05, 2018

\section{Introduction}

This survey-based cross-cultural study was designed to examine college-age women's body satisfaction, especially their concerns and appreciation of their physical bodies in the United States and China. This is an issue worth scrutiny because body satisfaction influences multiple aspects of an individual's life, ${ }^{1-4}$ from daily routines such as clothing choices to physical and mental health. Previous studies have shown that females, particularly young females, experience much higher pressure to pursue and meet certain physical beauty standards compared to males; $;^{1,5,6}$ therefore, females practice a greater amount and variety of appearance management behaviors than males. ${ }^{4,7} \mathrm{~A}$ majority of existing studies focus on the dieting or cosmetic surgery behaviors that can make long-term changes to a person's physical body. ${ }^{3,4}$ These studies investigate the relationships between those behaviors and health related issues, such as body weight control, eating disorders, and other physical and psychological issues. On the other hand, comparing to the above mentioned type of appearance management strategies, strategies such as styling and applying makeup have been discussed in a more theoretical and narrative way. ${ }^{2,7}$ The topic of "clothed-body" has been discussed to a great extent in the literature. It is generally recognized that clothing has always been a powerful tool for women to manage their body and appearance. However, a very limited number of solid researches have been conducted to explore the complicated relationships among women's physical body, perceived body in mind, and corresponding clothing choices. Therefore, this study proposes to investigate this issue. The article focuses on reporting results related to women's concerns of their physical bodies and how this informs their clothing choices.

Secondly, previous studies document differences of body satisfaction in different cultures, ${ }^{4-6,8-10}$ but this has not been well examined. It has been found that body satisfaction is highly related to individuals' internalized definitions of ideal physical beauty. ${ }^{4,7,11,12}$ However, beauty standards indeed vary among different socialcultural settings and natural environments. ${ }^{13}$ They also vary among individuals from different socioeconomic backgrounds and physiological conditions. ${ }^{14}$ In addition, beauty standards evolve with time and technology. ${ }^{15}$
Furthermore, as the old saying "beauty is in the eyes of beholder," individuals' concerns of their physical body, or body satisfaction is highly related to their internalized definitions of ideal physical beauty. ${ }^{12,13,15}$ Finally, the United States and China vastly distinct. Previous differences in the type and amount of information shared in the United States and China is minimized due to globalization, evolutions in information technology, and China's fast economic growth. However, there are still some deeply rooted differences, such as culturally established ideologies and biologically determined body shapes. Therefore, this cross-cultural study was conducted to:

a. Discuss college-age females' perceptions of their physical body in two countries that have different beauty standards;

b. Investigate the influences of culturally established beauty standards on young females' concerns of their physical body and corresponding clothing choices.

In other words, this cross-cultural study does not aim to study where beauty standards come from or examine what they are in two specific geographic locations with different cultural, social, economic, and geographic settings during a specific time period. Instead, it first acknowledges the existence of diverse beauty standards and then discusses their influences on young females' perception of their physical body and clothing choices. Based on findings from previous studies, six hypothesizes were developed as follows:

i. College-age females in the United States and China have different concerns about their appearance. ${ }^{3,9,13}$

ii. College-age females in the United States and China appreciate different parts of their body.

iii. College-age females in the United States physically exercise more than their Chinese counterparts. ${ }^{4}$

iv. College-age females in the United States spend more on clothing seasonally than their Chinese counterparts. ${ }^{7,16}$

v. College-age females in the United States are more independent when making clothing purchase decisions than Chinese consumers. ${ }^{17}$ 
vi. Media is influential when making clothing purchasing decisions for both groups. ${ }^{5,15,17}$

\section{Materials and methods}

This survey-based study was conducted in the United States and China. A pilot survey was distributed online in conjunction with a jeans study to undergraduate students in a northeastern university in the United States during 2011. Four types of questions were asked:

a. Background information such as gender, age, and ethnicity.

b. Questions related to physical body and body satisfaction such physical activity level, favorite and least favorite body parts.

c. Questions related to general clothing choices such as seasonal spending on clothing, self-reported size for tops and pants, influence of outside sources of opinion on clothing choices.

\section{d. Questions about jeans fit and style preferences.}

Data collected from the first three sections are reported and discussed in this study. Two questions were changed in the Chinese survey due to translation issues. To be specific, the participants in the United Stated were asked to select one body part out of thirteen choices, namely feet, calves, thighs, buttocks, hips, waist, chest, back, hands, arms, shoulders, neck, and head, as their favorite or least favorite body parts respectively. The Chinese group was presented with open-ended questions. This allowed the Chinese group to use their own language to indicate favorite and least favorite body parts. The updated survey was translated into Chinese by a bilingual researcher first, and then translated back into English by a different bilingual researcher to minimize misunderstandings resulting from language differences. In 2013, the final Chinese version of the survey was distributed to undergraduate students in an east coast university in mainland China. Differently, this time, the survey was sent out as a hard copy for the convenience of participants because they were more comfort with hard copies than online surveys during the designated time. However, there is no doubt this area is one of the most open, active and economically well-developed area across China.

\section{Results and discussion}

Only responses from female undergraduates to thirteen questions (the question of "gender" thus is not included) are presented and discussed here. Therefore, 313 valid responses in the United States and 194 valid responses in China were collected and analyzed. Both quantitative and qualitative data analysis techniques were utilized. SPSS software was utilized to examine quantitative data, and content analysis techniques together with NVivo software to understand qualitative data.

\section{Demographics}

Age: All 313 participants studying in the United States indicated their age in the survey, but only 173 out of 194 of the Chinese participants did the same thing. Significant differences in average age $(p=0.000)$ in these two groups of participants were found. On average, Chinese participants were 21 years old with a Standard Deviation (SD) of 1.273 , while the average of the American group was 19 (SD: 1.274). In addition, the two groups have different distributions of age (Figure 1). Comparing to the U.S. respondents, the Chinese respondents ranged in age. Even though both groups had over half of participants either 20 or 21 age groups, the Chinese group had much less participants younger than 20 and more participants older than 21 .
Ethnicity: The United States group was more diverse in terms of ethnicity. All Chinese participants who responded to this question identified themselves as Chinese Han people, while $61 \%$ of the U.S. participants were Caucasian, followed by Asian or Pacific Islander (22.7\%), African American (7\%), Latina (4.8\%), and others (4.5\%) (Figure 2).

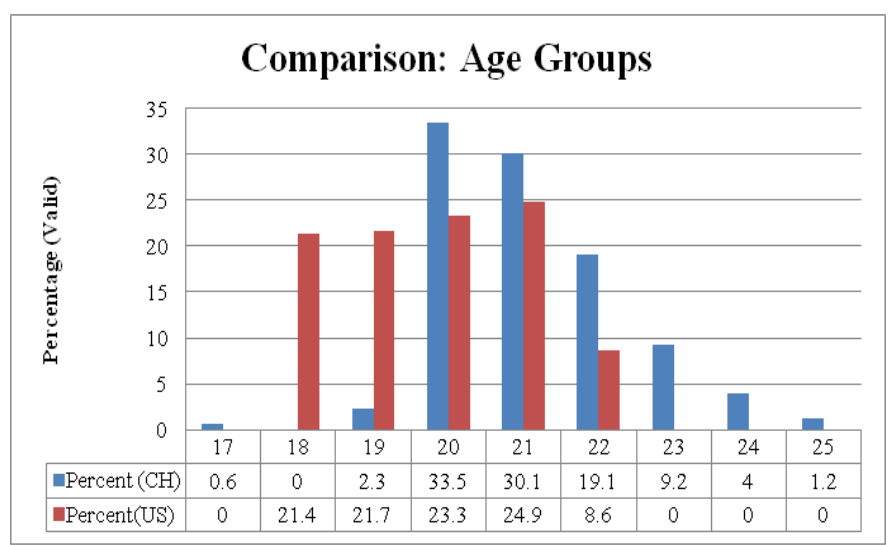

Figure I Age groups.

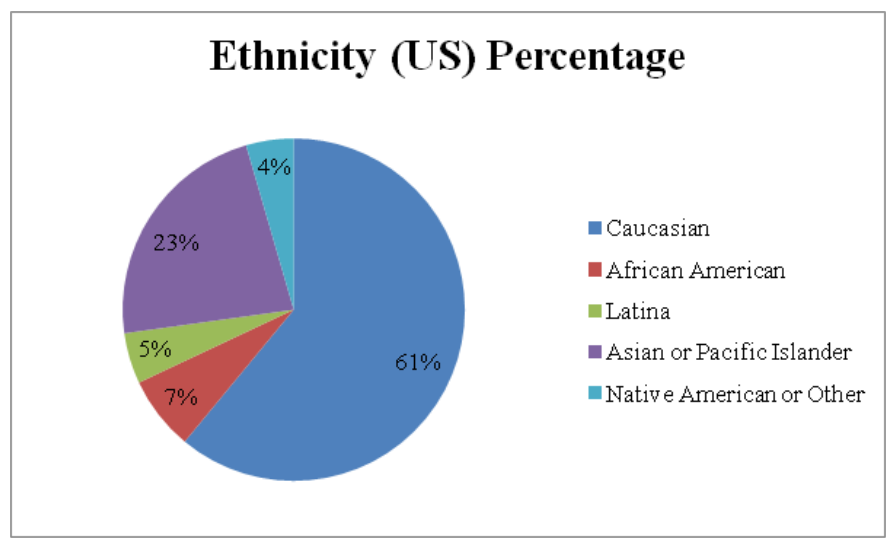

Figure 2 Ethnicity (US).

\section{Favorite body part and least favorite body part}

In responses to the questions of favorite and least favorite body part, the Chinese group indicated several body parts that did not fall into any of the thirteen categories presented to the U.S. groups. Therefore, the researcher first coded Face and Head into category "Face/Head", Stomach, Abdomen and Waist into category "Waist", Buttocks and Hip into category "Buttocks/Hip", and Legs, Thighs, Calves and Feet into category "Lower Limbs. Then, other parts such as Skin/Hair, Shoulder, Height, Body Build/Balance and Back were coded as "Others".

It was interesting to find that two groups of participants showed very different patterns in terms of favorite body parts $(\mathrm{p}=0.000)$ and least favorite body parts $(p=0.000)$. In general, it was found that the United States participants were in a complicated love-hate relationship with their middle to lower body parts. Some of them appreciate those areas very much, but some of them indicated that their lower body was the least favorite body area. No matter how, Waist, Hip and Lower Limbs were the places that received the most attention for this group of participants. On the contrary, the Chinese participants have complicated feelings toward their Lower Limbs (favorite 19.2\% 
VS least favorite $38.9 \%$ ), but not Waist and Hip areas. They simply indicated these constantly as their least favorite areas! In addition, fewer Chinese participants identified Hip/Buttocks (1.6\%) or Bust $(4.7 \%)$ as favorite areas than the American group (16.3\% and $12.1 \%$ respectively) did.

On the other hand, though the two groups indicated similar problematic areas, they appreciated different parts of their body. Particularly, in terms of favorite body parts, Chinese participants indicated a much higher satisfaction level for Arm/Hand (18.8\%) and Face/Head (17.2\%) areas than the US participants $(8.9 \%$ and $10.2 \%$ respectively) did. In addition, based on content analysis, the Chinese group placed much more attention to their facial features especially eyes and skin tone than the American group did (Figure 3).

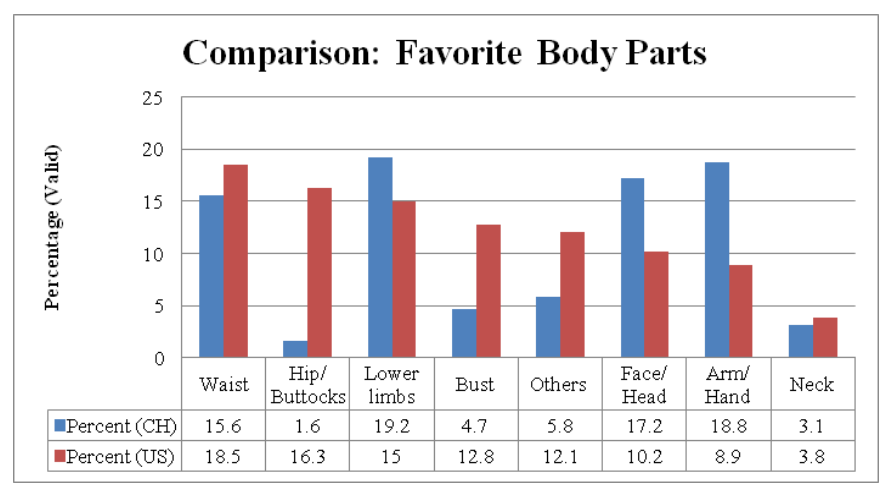

Figure 3 Favorite Body Parts.

In terms of least favorite body parts, Lower Limbs $(38.9 \%$, including legs as $31.6 \%$ ) were the least favorite body part for the Chinese participants, followed by Waist (13.5\%, including $4.7 \%$ for Stomach or Abdomen area) and Bust (10.4\%). In contrast, the biggest concern of the US participants was Lower Limbs (47.3\%, including Thighs as $37.4 \%$ ) followed by Waist $(17.9 \%)$, Hip (16\%) and Legs (9.9\%). Therefore, when the two categories "Legs" and "Thighs" were combined as a new category "Lower Limbs", it received the most dissatisfaction in both groups followed by Waist $(13.5 \%$ for Chinese and $17.9 \%$ for American participants), as shown in Figure 4. Therefore, this study supports hypothesis 1 regarding college-age females different concerns about their appearances in the United States and China, and hypothesis 2 regarding appreciation of different parts of their body. ${ }^{8,9}$

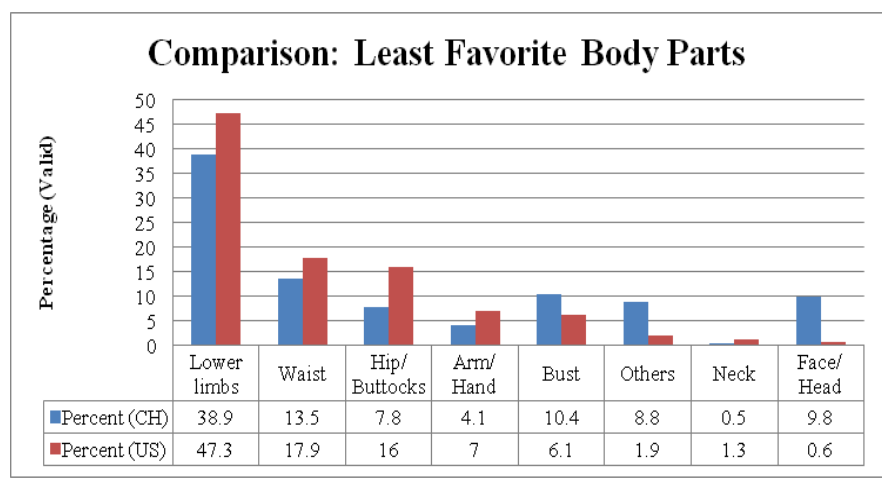

Figure 4 Least Favorite Body Part.

\section{Physical active level}

When asked about physical activity level, one Chinese and one American participant did not respond. Comparatively, American young females were significantly more active than their Chinese counterparts $(\mathrm{p}=0.000)$, as shown in Figure 5. It was found that $68.7 \%$ of the United States participants were at least moderately active (exercise more than twice a week) while $25.4 \%$ of their Chinese counterparts were moderately active. In fact, $43 \%$ of Chinese participants were just occasionally active (no exercise routine). $31.6 \%$ of them were just a bit active (only do daily activities) or not active at all. This supports hypothesis 3 regarding college-age females in the United States being more physically exercise than their Chinese counterparts.

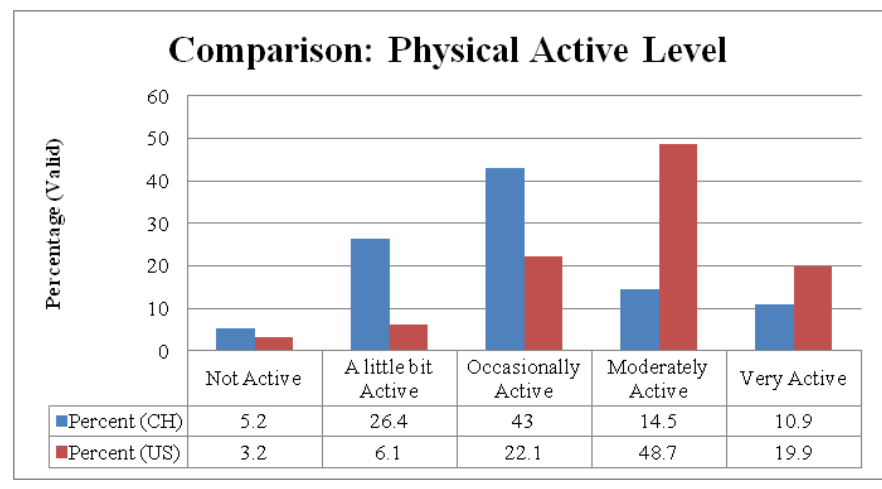

Figure 5 physical Active Level.

\section{Clothing choices}

Seasonal expense on clothing: Chinese participants' responses regarding seasonal expenses on clothing was originally described in Chinese Currency RMB, but was converted to U.S. Dollars according to the currency exchange rate at the time data collection was completed. Only a small portion of participants did not respond to this question, leaving $92.7 \%$ responding rate for the Chinese group and $99.7 \%$ for the U.S. group.

In terms of seasonal expenses on clothing, significantly different patterns was found $(p=0.004)$ between the two groups. On one hand, the collected data did not support the fourth hypothesis that college-age females studying in the United States spend more money on clothing than their Chinese counterparts do. The result actually proved the opposite: on average college-age females studying in the United States spend less money on clothing than their Chinese counterparts do. Originally, the hypothesis 4 was proposed based on a common knowledge that the average income in China was less than that in the United States. Therefore, general total seasonal expenses on clothing of the Chinese group would be less than that of the United States group. However, the collected data indicated that there was no significant between group differences existing in participants' annual income, while on average college-age Chinese females spent more money on clothing every season than the college-age females studying United States group did. Additionally, a majority of Chinese (65\%) participants spent less than $\$ 250$ on clothing seasonally than their United States counterparts $(52 \%)$. However, there were more American participants (18.3\%) than Chinese participants (12.2\%) who spent more than $\$ 500$ on clothing seasonally. Further research 
into topic is necessary. For instance, a percentage of spending on clothing and total expense would be more informative (Figure 6).

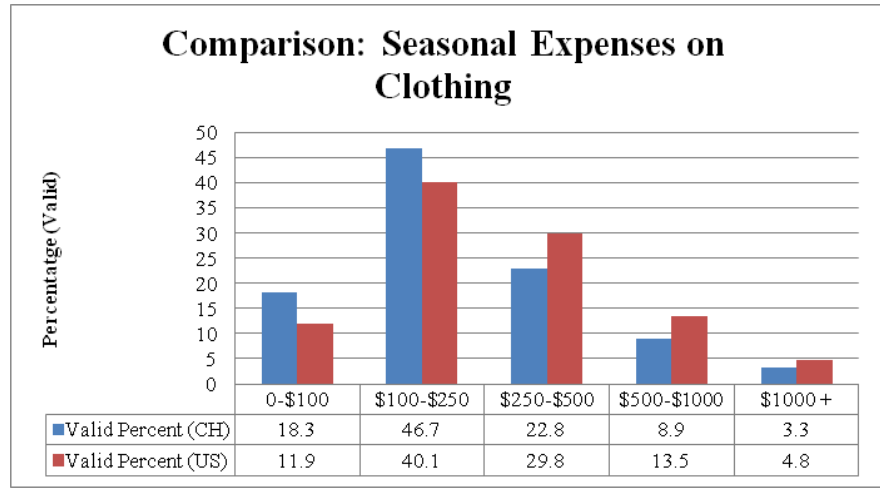

Figure 6 Seasonal Expenses on Clothing.

Size of pants: When asked to report the sizes of pants, $12.4 \%$ Chinese participants and $35.5 \%$ United States participants did not respond to this question or indicated that they did not know. There was a much higher percentage of missing data from the US group than the Chinese group, a possible reason is that the sizing systems used in the United States are much more diversified and complex.

Among those who indicated their pants size, size S was the most frequently selected size and the distribution of pants size in both group are slightly left-skewed (Figure 7). However, there was no significant between group difference $(\mathrm{p}=0.386)$. One explanation of this can be that usually size of pants is indicated in numerical numbers in the United States and in a scale of letters such as (XS-XL) in China. When the participants in the United Stated were responding to this question, they may have encountered difficulty in determining pant sizes based on the letter scale.

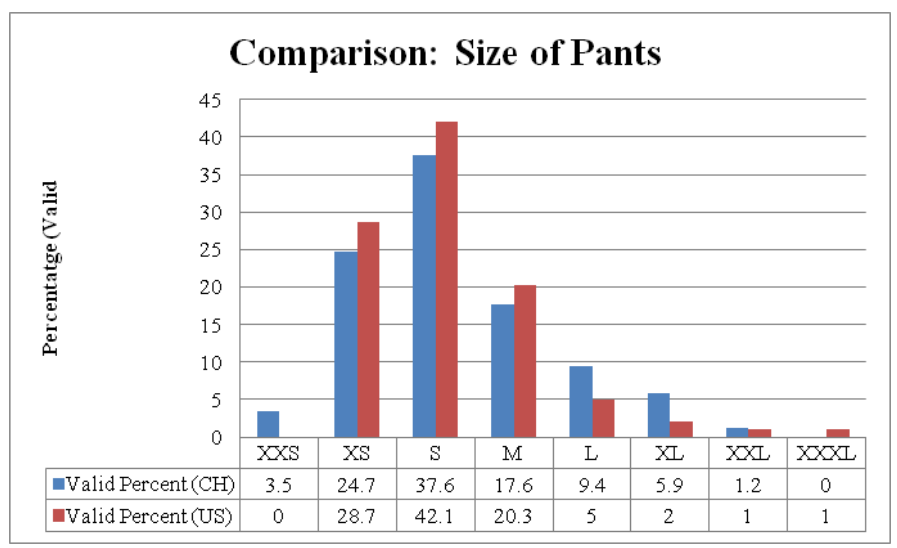

Figure 7 Sizes of Pants.

Another critical issue that needs to be emphasized and left for future exploration is that even though the same letter was used in a label, we cannot assume it indicates the same dimension or measurements for pants sold in different markets. Sizing is a complicated topic which could not be covered in this paper; however, this data provides foundational information to understand the distribution of sizes in the United States and China.

Size of tops: There is a similar left-skewed pattern for size of tops. The most frequently worn top size was size $\mathrm{S}$ for both groups (Figure 8).
However, there was significant between group difference $(\mathrm{p}=0.047)$ existing in sizes of tops.

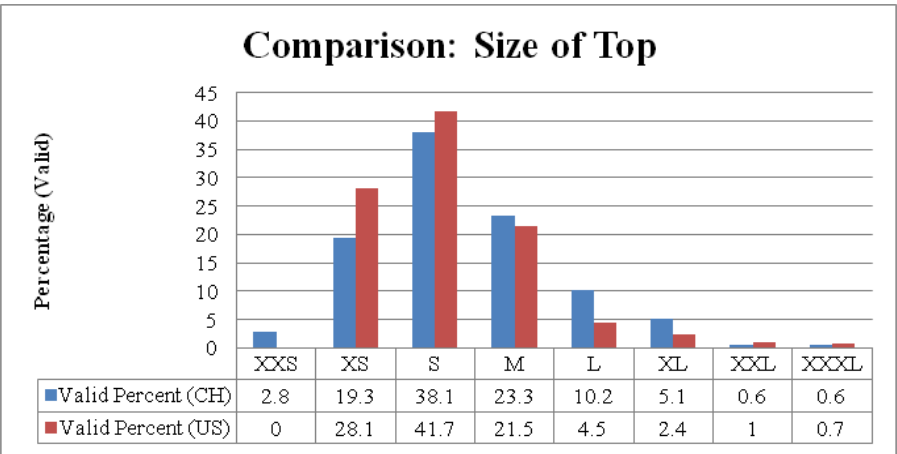

Figure 8 Size of Top.

Less than $10 \%$ Chinese participants $(9.3 \%)$ and United States participants $(8 \%)$ did not respond to this question or indicated that they did not have an answer to share, as their sized of tops changes with the brands of tops.

External influences on clothing choices: A scale of 1 to 5 was used to measure how external opinions influence individuals' clothing choices. This includes opinions from friends, family members, significant others, fashion trends, and media. In this scale, 1 meant no influence is perceived at all, 3 meant neutral, and 5 meant that a great amount of influence is perceived. For the United States participants, the score of fashion trend was calculated as an average of three questions: Celebrities; Fashion Designers and Model, while the Chinese group was directly asked about the influence of fashion trends on their clothing choices with a notice that fashion trends referred to trends established by celebrities, fashion designers, and models. Four Chinese participants and two U.S. participants did not respond to those questions.

Significant between group differences were identified for all of the five external influences $(p=0.000$ for all of the five external influences). Among the five external influences, comparing to the Chinese participants, the United States participants perceived less influence from family members, significant other, fashion trends, and media on their clothing choices, but more influence from friends (Table 1). Thus, the hypothesis 5 regarding U.S. college-age females' more independent when making clothing purchase decisions compared to Chinese consumers is partially supported. This finding is interesting to researchers. It is generally recognized that individualism is popular in the United States while collectivism is generally valued in China. Therefore, the hypothesis 5 was constructed based on an assumption that college-age females studying in the United Stated were more independent in decision-making than their Chinese counterparts were.

In general, clothing choices of the United States group were barely influenced by three out of the five external forces, but not Friends (average rating was 3.41) and Fashion Trends (average rating was 3.10). Differently, the Chinese group was affected by fashion trends the most (average rating was 3.23), while they also perceived influences from other Family Members (average rating was 3.2). Friends' opinions and Media also had limited impact on Chinese participants' clothing choices. Other than that, it is also interesting to find that neither of the two groups believed media had great influence on their clothing choices, while it has been well reported in literature that media has great influence over women's clothing choices. ${ }^{1,4,5,16,17}$ 
Therefore, the last hypothesis that media is influential when making clothing purchasing decisions for both groups is rejected. However, we need to be cautious in interpreting it as a self-reported response.

\section{Limitations}

The first limitation of this study is the comparability of two groups of participants, because these two groups of participants had Table I Comparison of Average Perceived Level of Influences somewhat different distributions of age and ethnicity. In addition, only a small proportion of United States participants were in fashionrelated majors, but over $90 \%$ of the Chinese participants were in fashion-related programs. Secondly, body satisfaction is a multifaceted topic. It includes concerns and appreciation on different body parts, but it is not limited to that. More and deeper understanding of this topic is needed.

\begin{tabular}{llllll}
\hline & Friends & Family members & Significant other & Fashion trends & Media \\
\hline United States & 3.41 & 2.86 & 2.72 & 3.1 & 2.69 \\
China & 3.07 & 3.2 & 2.99 & 3.23 & 3.05
\end{tabular}

Future research might be conducted regarding how majors as well as levels of exposures to fashion media influence female college students' body satisfaction and clothing choices. In addition, an interview-based study can further explore college-age females' fondness and concerns of their physical appearance and body. Lastly, a comprehensive study using objective measures other than selfreported information is vital to further understand college females' body satisfaction and perceived external influences on clothing choices.

\section{Conclusion}

As the world is experiencing fast-paced globalization, particularly China as a cite for inter-cultural exchanges, a number of studies report that western beauty standards of thinness and physical fitness are influencing traditional Chinese beauty standards. ${ }^{4,13,15}$ Thus, Chinese women's appearance management behaviors are evolving. ${ }^{4}$ Second, comparing to other age groups, college-age females are relatively vulnerable to external standards of beauty and others opinions. ${ }^{5,8,17}$ Satisfactory levels of physical appearance and body may place great impacts on college-age female's adoption of appearance management strategies such as dressing and weight management., ${ }^{4,6,16}$ However, such behaviors may back fire if there is no thorough understanding of the fondness and concerns of their body and the mechanism behind. ${ }^{11}$

This study confirms that college-age females in the United States and China have different of fondness and dissatisfaction toward their different body parts. To be specific, this study confirms the first hypothesis that college-age females in the United States and China have different concerns about their appearance. It was found that concerns about physical appearance and body were significantly different between these two groups. The second hypothesis was also supported as the two groups of participants appreciated different parts of their body. Additionally, college-age females in the United States exercise significantly more regularly than their Chinese counterparts, which confirm the third hypothesis. The fourth hypothesis was also support as college-age females in the United States reported more seasonal spending on clothing than Chinese participants. On the other hand, contrary to the prediction for hypothesis four, in terms of making clothing purchasing decisions, the college-age females in the United States were influenced by their friends' opinions more than the Chinese group were. The fifth hypothesis was also rejected. It was surprising that neither of the two groups believed media had a great impact on their clothing choices, while literature suggests that media has great influence over women's clothing choices.
To conclude, college-age females studying in the United States and China both have concerns about their physical appearance and body, but in regards to different areas. Both groups admitted that they made efforts to pursue or maintain ideal an appearance and body, but they tended to use different strategies. Particularly, the United States groups relied on exercise more than the Chinese participants. When it came to clothing choices, surprisingly, both groups reported that they were somewhat independent in regards to making clothing choices. They both believed that media did not greatly affect their clothing choices.

With an understanding of college-age females' fondness and concerns about their physical body as well as their current patterns of clothing consumption, rational adoptions of appearance management behaviors can be educated. On the other hand, this study provides valuable information such as consumers' needs and preferences for the fashion industry, particularly companies whose target consumers include college-age females.

\section{Acknowledgements}

There is no individual other than the author who contributed to this work. No grant supported this study.

\section{Conflict of interest}

There is no financial interest or any conflict of interest.

\section{References}

1. Dunkel TM, Davidson D, Qurashi S. Body satisfaction and pressure to be thin in younger and older Muslim and non-Muslim women: The role of Western and non-Western dress preferences. Body Image. 2010;7(1):56-65.

2. Shin E, Baytar F. Apparel Fit and Size Concerns and Intentions to Use Virtual Try-On: Impacts of Body Satisfaction and Images of Models' Bodies. Clothing \& Textile Research J. 2014;32(1):20-33.

3. Mustapic J, Marcinko D, Vargek P. Eating behaviours in adolescent girls: the role of body shame and body dissatisfaction. Eating and Weight Disorders-Studies on Anorexia, Bulimia and Obesity. 2015;20(3):329-335.

4. Xu X, Mellor D, Kiehne M, et al. Body dissatisfaction, engagement in body change behaviors and sociocultural influences on body image among Chinese adolescents. Body Image. 2010;79(2):156-164.

5. Chen H, Jackson T. Gender and age group differences in mass media and interpersonal influences on body dissatisfaction among Chinese adolescents. Sex Roles. 2012;66(1-2):3-20. 
6. Maphis LE, Martz DM, Bergman SS., et al. Body size dissatisfaction and avoidance behavior: How gender, age, ethnicity, and relative clothing size predict what some won't try. Body Image. 2013;10(3):361-368.

7. Kim H, Damhorst ML. The relationship of body-related self-discrepancy to body dissatisfaction, apparel involvement, concerns with fit and size of garments, and purchase intentions in online apparel shopping. Clothing \& Textile Research J. 2010;28(4):239-254.

8. Li Y, Hu X, Ma W, et al. Body image perceptions among Chinese children and adolescents. Body Image. 2005;2(2):91-103.

9. Mellor D, Fuller-Tyszkiewicz M, McCabe MP, et al. A test of the resource security and the body mass index reference point hypotheses of body dissatisfaction amongst adolescents in eight countries. Ethnicity \& Health. 2014;19(5):548-564.

10. Rakhkovskaya LM, Vartanian LR. Sociocultural and identity predictors of body dissatisfaction in ethnically diverse college women. Body Image. 2016;16:32-40.

11. Polivy J, Garner DM, Garfinkel PE. Causes and consequences of the current preference for thin female physiques. In: Herman CP, Zanna M, Huggins ET, editors. Physical Appearance, Stigma, and Social Behavior: The Ontario symposium. New Jersey: Erlbaum Hillsdale; 1986. 298 p.
12. Swami V, Tran US, Brooks LH, et al. Body image and personality: Associations between the Big Five Personality Factors, actual $\square$ ideal weight discrepancy, and body appreciation. Scandinavian J Psychology. 2013;54(2):146-151.

13. Anderson JL, Crawford CB, Nadeau J, et al. Was the Duchess of Windsor right? A cross-cultural review of the socioecology of ideals of female body shape. Ethology \& Sociobiology. 1992;13(3):197-227.

14. Sobal J, Stunkard AJ. Socioeconomic status and obesity: A review of the literature. Psychological Bulletin. 1989;105(2):260-275.

15. Swami V. Cultural Influences on Body Size Ideals: Unpacking the Impact of Westernization and Modernization. European Psychologist. 2015;20(1):44-51.

16. Hsu HJ, Burns LD. Clothing evaluative criteria: A cross-national comparison of Taiwanese and United States consumers. Clothing \& Textile Research Journal. 2002;20(4):246-252.

17. Javier SJ, Belgrave FZ. An Examination of Influences on Body Dissatisfaction Among Asian American College Females: Do Family, Media, or Peers Play a Role?. J American College Health. 2015;63(8):579-583. 